\title{
BMJ Open Association of immune recovery with hyperlipidaemia and apolipoprotein gene polymorphisms following highly active antiretroviral therapy in a cohort of Chinese HIV patients
}

\author{
Denise Pui-Chung Chan, ${ }^{1}$ Man-Po Lee ${ }^{2}$ Ngai-Sze Wong, ${ }^{1}$ Ross Ka-Kit Leung, ${ }^{1}$ \\ Claire Melinda Naftalin, ${ }^{1}$ Shui-Shan Lee ${ }^{1}$
}

To cite: Chan DP-C, Lee M-P, Wong N-S, et al. Association of immune recovery with hyperlipidaemia and apolipoprotein gene polymorphisms following highly active antiretroviral therapy in a cohort of Chinese HIV patients. BMJ Open 2016;6:e010998. doi:10.1136/bmjopen-2015010998

- Prepublication history and additional material is available. To view please visit the journal (http://dx.doi.org/ 10.1136/bmjopen-2015010998).

Received 28 December 2015 Revised 18 February 2016 Accepted 10 March 2016

CrossMark

\footnotetext{
${ }^{1}$ Stanley Ho Centre for Emerging Infectious Diseases, The Chinese University of Hong Kong, Shatin, Hong Kong, People's Republic of China

${ }^{2}$ Department of Medicine, Queen Elizabeth Hospital, Kowloon, Hong Kong, People's Republic of China
}

Correspondence to Dr Shui-Shan Lee; sslee@cuhk.edu.hk

\section{ABSTRACT}

Objective: To examine the associations between CD4 recovery, dyslipidaemia and apolipoprotein (APO) gene single nucleotide polymorphisms (SNPS) following highly active antiretroviral therapy (HAART).

Design: Retrospective observational cohort study. Setting: A major HIV care clinic in Hong Kong. Participants: 197 Chinese treatment-naïve HIV patients.

Outcome measures: Maximum CD4 count and its rise 2-3 years after HAART initiation and their association with abnormal total cholesterol (TC), triglyceride (TG) and 8 selected APO SNP at multiple time points.

Results: Before HAART, abnormal levels of TC, TG, high-density lipoprotein cholesterol and low-density lipoprotein cholesterol were detected in 13\%, $26 \%$, $59 \%$ and $19 \%$ of the recruited patients, respectively. APOA5 - 1131T>C and C.553G >T were significantly associated with high pre-HAART TG while APOE $2198 \mathrm{C}>\mathrm{T}$ was correlated with high TG at baseline and/ or a rise 2-3 years following HAART initiation. Poor CD4 achievement, defined as the highest CD4 count $<350 / \mu \mathrm{L}$ and a net gain of $<100 / \mu \mathrm{L}$, was associated with a low CD4 count $\leq 200 / \mu \mathrm{L}$ at baseline and a rise of TC beyond $5.17 \mathrm{mmol} / \mathrm{L}$ following HAART with or without the use of antilipid agents. Conversely, satisfactory CD4 achievement was associated with APOC3 3238GG genotype. Applying a linear generalised estimating equation, APOA5 $-1131 \mathrm{~T}>\mathrm{C}$ was shown to be a predictor of a weaker temporal trend for CD4 response in the presence of a low baseline CD4 $\leq 200 / \mu \mathrm{L}$.

Conclusions: Dyslipidaemia plays a predictive role in impacting immunological recovery following HAART, which could be partly explained by the APO gene SNP.

\section{INTRODUCTION}

The complex inter-relationships between hyperlipidaemia and HIV infection have
Strengths and limitations of this study

- Analyses of longitudinal data collected from a cohort of Chinese patients receiving treatment in accordance with standard protocol.

- Both lipid levels and information on the selected apolipoprotein (APO) gene single nucleotide polymorphism were available to examine their impacts on immunological recovery following highly active antiretroviral therapy.

- Only eight APO genes were selected for analysis in the study.

- CD4 count alone was used for assessing immunological recovery.

continued to be unravelled, paralleling the progress of highly active antiretroviral therapy (HAART). In treatment-naïve patients, advanced HIV diseases have been reported to be associated with high plasma triglyceride (TG), low high-density lipoprotein cholesterol (HDL-C) and variable levels of lowdensity lipoprotein cholesterol (LDL-C) and very-LDL-C, $^{1-4}$ the relative importance of which depends also on the patients' nutritional status. ${ }^{5}$ With HAART, hyperlipidaemia has become increasingly reported, notably in association with regimens composed of ritonavir-boosted protease inhibitors (PIs). ${ }^{6}$ Lipid profile may also improve with the use of antilipid agents and the strategic selection of antiretrovirals (ARVs). ${ }^{7}$ Overall, the characteristics of HIV-related cardiovascular and metabolic complications have been extensively researched. ${ }^{5} 8$ As an important outcome of HAART, immunological recovery and the potential influences of hyperlipidaemia are becoming an emerging concern. Retrospective cohort studies suggested a positive correlation between HDL-C and nadir 
CD4 cell count. ${ }^{1}{ }^{4}$ Similar patterns were reported in Asian communities, ${ }^{3}$ children ${ }^{9}$ and women. ${ }^{10}$ In the latter study, a higher CD4 count was associated with higher apolipoprotein (APO) B. Separately, an African cohort study reported that the LDL/HDL-C ratio and anthropometric markers contributed to the variability of CD4 reconstitution after 6 months of HAART. ${ }^{11}$

From the genetic perspective, HAART-associated hyperlipidaemia was under the influence of various forms of genetic polymorphisms, similar to the situation in non-HIV adults. ${ }^{12} 13$ The prevalence of such polymorphisms did vary from one population to another. A study in the Chinese population reported that APOA5 gene $-1131 \mathrm{~T}>\mathrm{C}$ and $\mathrm{c} .553 \mathrm{G}>\mathrm{T}$ were associated with high TG and could predict coronary artery disease. ${ }^{14}$ A crosssectional study demonstrated that the same polymorphisms at APOA5 could affect circulating CD4 cell levels in chronically HIV-infected patients, ${ }^{15}$ inferring the effects of lipid metabolism on HAART-associated immune recovery. These results echoed the analyses conducted on a South African cohort, suggesting that metabolic parameters might account for as much as $44 \%$ of CD4 recovery following HAART. ${ }^{13}$ While these studies provided insights into the relationships between dyslipidaemia, host genetic polymorphism and CD4 recovery, a definitive conclusion is difficult partly because of the limitations inherent in the studies, many of which were cross-sectional in design. There was also scarcity of data on the temporal changes of lipid/immune markers, superimposed on the coexistence of confounders. These backgrounds have prompted us to conduct a retrospective cohort study on HIV-positive treatment-naïve patients of the same ethnicity with data from multiple time points to test the relationships between lipid/genetic polymorphism and CD4 recovery pattern.

\section{PATIENTS AND METHODS}

The study was conducted at the HIV specialist service of Queen Elizabeth Hospital in Hong Kong, an institution that looks after about a quarter of all reported HIV/ AIDS cases in the territory. Following written informed consent, HIV-positive patients were recruited if they were Chinese and had been put on HAART, in accordance with local clinical guidelines founded on a CD4-guided approach to treatment initiation. In brief, treatment was recommended when the CD4 count fell below $350 / \mu \mathrm{L}$. The following data were retrieved from clinical records anonymously: demographics; dates of HIV diagnosis and HAART initiation; HAART regimens - divided into either PI-based or non-nucleoside reverse transcriptase inhibitor (NNRTI)-based; CD4 and viral load measurements every 3-4 months; lipid profilesTG, total cholesterol (TC), HDL-C, LDL-C; and the use of lipid-lowering treatment at baseline and/or following HAART.

During a 9-month study period, all eligible cases were selected for analysis if they were ARV naïve at baseline, had been on their first HAART regimen $\geq 2$ years without interruptions, had lipid measurements, a viral load and CD4 records made at baseline and during treatment, and had achieved viral suppression (defined as $\leq 500 / \mathrm{mL}$ ) as a result of HAART. Patients with missing data on CD4 changes and lipid profiles were excluded. Blood samples were collected from eligible patients followed by the extraction of genomic DNA using QIAmp DNA kit (Qiagen) according to the manufacturer's protocol. The following candidate single nucleotide polymorphisms (SNPs) of APO genes were tested: APOA5 -1131T $>$ C (rs662799), c.56C $>$ G $(\mathrm{S} 19 \mathrm{~W})$ (rs3135506) and c.553G $>\mathrm{T}$ (rs2075291); APOC3 $-482 \mathrm{C}>\mathrm{T} \quad(\mathrm{rs} 2854117), \quad-455 \mathrm{~T}>\mathrm{C} \quad(\mathrm{rs} 2854116) \quad$ and 3238C $>$ G (rs5128); and APOE 2060T $>$ C (rs429358) and 2198C $>$ T (rs7412) by allelic discrimination using the custom TaqMan SNP Genotyping Assay (Applied Biosystems). ${ }^{16} 17$ Selection of these SNPs was based on results published in the literature as regards their association with dyslipidaemia following HAART. ${ }^{12} 1518$

Lipid abnormalities were diagnosed according to the cut-off values defined by the US National Cholesterol Education Program Adult Treatment Panel III (NCEP-ATPIII) guidelines: TG $\geq 1.7 \mathrm{mmol} / \mathrm{L}$; TC $\geq 5.17 \mathrm{mmol} / \mathrm{L} ; \quad$ HDL-C $<1.03 \mathrm{mmol} / \mathrm{L}$; LDL-C $\geq 3.36 \mathrm{mmol} / \mathrm{L}^{19}$ Allele frequencies of SNPs were calculated by direct counting. The Hardy-Weinberg equilibrium (HWE) for each SNP was tested using a $\chi^{2} \mathrm{HWE}$ test calculator, considering equilibrium for $\mathrm{p}>0.05$. Linear generalised estimating equations (GEEs) with an unstructured working correlation matrix were performed to examine the variation of selected SNP, hyperlipidaemia (TC and TG abnormality) and baseline $\mathrm{CD} 4 \leq 200 / \mu \mathrm{L}$ (independent variables) with a CD4 count across time (outcome variable). Sequential Bonferroni was used to adjust for multiple comparisons in GEE. Separately, univariate analysis (OR) was used to compare between patients with suboptimal and satisfactory CD4 recovery, followed by multivariate analyses. In this study, satisfactory CD4 recovery was defined as the attainment of the highest CD4 count above $350 / \mu \mathrm{L}$ at years $2-3$ and a net gain of $>100 / \mu \mathrm{L}$ above baseline, following criteria adopted in a previous study. ${ }^{20}$ All statistical analyses were performed in SPSS V.22 (IBM Corp) and R V.3.2.1.

\section{RESULTS}

\section{General characteristics of recruited patients}

Between August 2011 and March 2012, a total of 327 ARV-naïve patients attending the clinic were approached. Of these, $197(60 \%)$ eligible patients were recruited after exclusion of cases with missing data. The general characteristics of recruited patients are displayed in table 1. Overall, their male-to-female ratio was 6.9:1, with a median age of 37 (IQR 31-44). The median pretreatment CD4 count and viral load were $103 / \mu \mathrm{L}$ (IQR 29-212) and $97000 / \mathrm{mL}$ (IQR $34000-279000)$, respectively. The median duration of observation was 
Table 1 General characteristics of treatment-naïve HIV patients at baseline before HAART initiation $(n=197)$

\begin{tabular}{|c|c|c|}
\hline & n (\%) & Median (IQR) \\
\hline \multicolumn{3}{|l|}{ Demographics } \\
\hline Male gender & $172(87)$ & \\
\hline HIV age $>35$ & $116(59)$ & \\
\hline Months of monitoring & & $27(23-60)$ \\
\hline \multicolumn{3}{|c|}{ Baseline immune and viral markers } \\
\hline CD4 cells $/ \mu \mathrm{L}$ & & $103(29-212)$ \\
\hline Cell count $\leq 200 / \mu \mathrm{L}$ & $139(71)$ & \\
\hline VL copies/mL; n=191 & & $\begin{array}{l}97000 \\
(34000-279000)\end{array}$ \\
\hline $\begin{array}{l}\text { VL unsuppressed } \\
(>500 / \mathrm{mL})\end{array}$ & $191(100)$ & \\
\hline $\begin{array}{l}\mathrm{VL}>100000 \\
\text { copies } / \mathrm{mL}\end{array}$ & $92(48)$ & \\
\hline \multicolumn{3}{|l|}{ Baseline lipid status } \\
\hline TG mmol/L; $(n=141)$ & & $1.3(1-1.7)$ \\
\hline $\mathrm{TG} \geq 1.7 \mathrm{mmol} / \mathrm{L}$ & $36(26)$ & \\
\hline $\mathrm{TC} \mathrm{mmol} / \mathrm{L} ;(\mathrm{n}=141)$ & & $4(3.5-4.7)$ \\
\hline $\mathrm{TC} \geq 5.17 \mathrm{mmol} / \mathrm{L}$ & $18(13)$ & \\
\hline HDL-C mmol/L; $(n=83)$ & & $1(0.8-1.2)$ \\
\hline $\mathrm{HDL}-\mathrm{C}<1.03 \mathrm{mmol} / \mathrm{L}$ & $49(59)$ & \\
\hline LDL-C mmol/L; ( $n=81)$ & & $2.4(1.8-3)$ \\
\hline LDL-C $\geq 3.36 \mathrm{mmol} / \mathrm{L}$ & $15(19)$ & \\
\hline $\begin{array}{l}\text { Antilipid treatment at } \\
\text { baseline }\end{array}$ & $18(9)$ & \\
\hline \multicolumn{3}{|l|}{ Antiretroviral therapy } \\
\hline HAART initiation age & & $39(32-45)$ \\
\hline Initiation age $>35$ & $129(65)$ & \\
\hline \multicolumn{3}{|l|}{ First HAART regimen } \\
\hline NNRTI-based & $148(75)$ & \\
\hline Pl-based & $49(25)$ & \\
\hline
\end{tabular}

HAART, highly active antiretroviral therapy; HDL-C, high-density lipoprotein cholesterol; LDL-C, low-density lipoprotein cholesterol; NNRTI, non-nucleoside reverse transcriptase inhibitor; PI, protease inhibitors; TC, total cholesterol; TG, triglyceride; VL, viral load.

27 months (IQR 23-60). One hundred and forty-eight patients $(75 \%)$ have been put on NNRTI-based ARV therapy, and $49(25 \%)$ on PI-based therapy regimens. At study entry, patients in the NNRTI-treated and PI-treated groups were similar with regard to age, gender, nadir CD4 count and HIV viral load. All patients had demonstrable virus suppression with a viral load $\leq 500 / \mathrm{mL}$ after the initiation of HAART.

\section{Lipid profile and APO gene polymorphisms}

At baseline, a quarter (26\%) of the patients had a high $\mathrm{TG} \geq 1.7 \mathrm{mmol} / \mathrm{L}$. The proportions with abnormal TC, HDL-C and LDL-C were $13 \%, 59 \%$ and $19 \%$ respectively, while $18(9 \%)$ had already been receiving antilipid treatment before HAART. The genotype distributions of the SNPs in the tested APO genes were in HWE ( $p>0.05)$, except for APOA5 c.56C $>\mathrm{G}(\mathrm{S} 19 \mathrm{~W})$, in which case only one patient was tested positive for the SNP (see online supplementary table S1). Two mutated alleles, APOA5 -1131T $>\mathrm{C}$ and c.553G $>\mathrm{T}$, were significantly associated with a high pre-HAART TG (ie, $\geq 1.7 \mathrm{mmol} / \mathrm{L} ; 81 \%$ vs $55 \%$, OR $=3.43$, 95\% CI 1.38 to $8.51 ; 28 \%$ vs $10 \%$, OR $3.32,95 \%$ CI 1.27 to 8.68 , respectively). There was otherwise no association between baseline lipids and the other APO gene SNPs (see online supplementary table S2(A)). Likewise, no difference was seen between homozygous and heterozygous SNP-containing genotypes as regards their association with dyslipidaemia (results not shown). Concerning the impacts of ARV therapy, patients on NNRTI were more likely to have abnormal HDL-C $<1.03 \mathrm{mmol} / \mathrm{L}$ at baseline compared with those on PI ( $39 \%$ vs $67 \%$, OR=3.11, 95\% CI 1.15 to 8.41 ).

Following the initiation of HAART, 44/94 (47\%) of the recruited participants with a normal lipid profile at baseline had developed dyslipidaemia at years 2-3-elevated TG 27/72 (38\%), TC 26/85 (31\%), LDL-C 6/24 $(25 \%)$ and reduced HDL-C 2/14 (14\%)-while 3/93 (3\%) had started on antilipid agents. There was no difference between PI-based and NNRTI-based regimens in their development of dyslipidaemia (results not shown). Expanding the definition of dyslipidaemia to include abnormal lipid levels after HAART as well as the use of antilipid agents, the mutated APOA5 allele -1131T>C remained significantly associated with abnormal TG (see online supplementary table S2(B)) Separately, the mutated APOE allele 2198C $>$ T was associated with a rise in TG at baseline and/or years 2-3 following HAART initiation, with the inclusion of patients on antilipid treatment. There was, however, no association between abnormal TG at years 2-3 following HAART and any one of the eight APO SNPs for patients with normal lipid levels at baseline (see online supplementary table S2(C)). As for abnormal TC and LDL-C, there was again no genetic association with any of the tested SNPs at any specific time point following HAART.

\section{Immune recovery and its correlates}

In the subsequent analyses, satisfactory CD4 achievement was defined as the attainment of the highest CD4 count above $350 / \mu \mathrm{L}$ at years $2-3$ and a net gain of $>100 / \mu \mathrm{L}$ above baseline. ${ }^{20}$ Results of 140 patients were available for the analyses, of which $75(53.5 \%)$ could be classified as satisfactory CD4 achievers. Comparing between low and satisfactory CD4 achievers, a low baseline $\mathrm{CD} 4$ count $\leq 200 / \mu \mathrm{L}$ was a negative associating factor $(86 \%$ vs $69 \%, \mathrm{OR}=0.36, \mathrm{p}=0.02$; table 2$)$. The extent of CD4 recovery was not related to baseline dyslipidaemia, but was associated with a rise of TC beyond $5.17 \mathrm{mmol} / \mathrm{L}$ with or without the use of antilipid agents following HAART. Age, baseline viral load and gender did not show any relationship with $\mathrm{CD} 4$ achievement. The allelic frequency of APO SNPs tested did not show any significant difference between low and satisfactory CD4 achievers. Patients homozygous for the mutated APOC3 allele 3238C $>\mathrm{G}$ were more likely to give a satisfactory $\mathrm{CD} 4$ achievement compared with heterozygous patients (OR 3.74, 95\% CI 1.07 to 13.13; see online 
Table 2 Comparison between satisfactory CD4 achievers (CD4>350/ $\mu \mathrm{L}$ at years $2-3$ with a net gain of $>100 / \mu \mathrm{L}$ from baseline, $n=75$ ) and low CD4 achievers ( $n=65)$ in univariate analysis

\begin{tabular}{|c|c|c|c|c|c|c|}
\hline & \multicolumn{2}{|c|}{$\begin{array}{l}\text { Low CD4 } \\
\text { achievers }(n=65)\end{array}$} & \multicolumn{2}{|c|}{$\begin{array}{l}\text { Satisfactory CD4 } \\
\text { achievers }(n=75)\end{array}$} & \multicolumn{2}{|l|}{ OR } \\
\hline & $\bar{n}$ & Per cent & $\overline{\mathbf{n}}$ & Per cent & $\overline{\text { OR }}$ & $95 \% \mathrm{Cl}$ \\
\hline \multicolumn{7}{|l|}{ Demographics and baseline HIV status } \\
\hline Male gender & 54 & 83 & 63 & 84 & 1.07 & 0.44 to 2.62 \\
\hline HIV diagnosis at age $>35$ & 37 & 57 & 44 & 59 & 1.07 & 0.55 to 2.1 \\
\hline CD4 $\leq 200$ cells $/ \mu \mathrm{L}$ & 56 & 86 & 52 & 69 & 0.36 & 0.15 to $0.86^{*}$ \\
\hline NNRTI-based regimen & 51 & 78 & 56 & 75 & 0.81 & 0.37 to 1.78 \\
\hline \multicolumn{7}{|l|}{ Apolipoprotein gene SNP (mutated allele) } \\
\hline APOA5 -1131T>C & 44 & 68 & 42 & 56 & 0.61 & 0.3 to 1.21 \\
\hline APOA5 c.56C >G (S19W) & 1 & 2 & 0 & 0 & / & \\
\hline APOA5 c.553G $>\mathrm{T}$ & 7 & 11 & 10 & 13 & 1.27 & 0.46 to 3.57 \\
\hline APOC3 -482C>T & 40 & 62 & 44 & 59 & 0.89 & 0.45 to 1.75 \\
\hline APOC3 -455T>C & 43 & 66 & 42 & 56 & 0.65 & 0.33 to 1.29 \\
\hline APOC3 $3238 \mathrm{C}>\mathrm{G}$ & 38 & 58 & 36 & 48 & 0.66 & 0.34 to 1.28 \\
\hline APOE 2060C>T† & 10 & 15 & $8 / 74$ & 11 & 0.67 & 0.25 to 1.81 \\
\hline$A P O E 2198 T>C$ & 8 & 12 & 12 & 16 & 1.36 & 0.52 to 3.56 \\
\hline \multicolumn{7}{|l|}{ Lipid at baseline } \\
\hline On antilipid treatment & 3 & 5 & 2 & 3 & 0.57 & 0.09 to 3.5 \\
\hline $\mathrm{TG} \geq 1.7 \mathrm{mmol} / \mathrm{L} \dagger$ & $12 / 39$ & 31 & $13 / 58$ & 22 & 0.65 & 0.26 to 1.63 \\
\hline $\mathrm{TC} \geq 5.17 \mathrm{mmol} / \mathrm{L} \dagger$ & $5 / 39$ & 13 & $7 / 58$ & 12 & 0.93 & 0.27 to 3.18 \\
\hline LDL-C $\geq 3.36 \mathrm{mmol} / \mathrm{L} \dagger$ & $3 / 17$ & 18 & $5 / 25$ & 20 & / & \\
\hline $\mathrm{HDL}-\mathrm{C}<1.03 \mathrm{mmol} / \mathrm{L} \dagger$ & $11 / 18$ & 61 & $15 / 26$ & 58 & / & \\
\hline \multicolumn{7}{|l|}{ Lipid changes in first $2-3$ years } \\
\hline Put on antilipid treatment & 4 & 6 & 5 & 7 & 1.09 & 0.28 to 4.24 \\
\hline TG from normal to $\geq 1.7 \mathrm{mmol} / \mathrm{L} \dagger$ & $9 / 27$ & 33 & $18 / 45$ & 40 & 1.33 & 0.49 to 3.62 \\
\hline $\mathrm{TC}$ from normal to $\geq 5.17 \mathrm{mmol} / \mathrm{L} \dagger$ & $16 / 34$ & 47 & $10 / 51$ & 20 & 0.27 & 0.1 to $0.72^{\star}$ \\
\hline LDL-C from normal to $\geq 3.36 \mathrm{mmol} / \mathrm{L} \dagger$ & $4 / 11$ & 36 & $2 / 13$ & 15 & / & \\
\hline HDL-C from normal to $<1.03 \mathrm{mmol} / \mathrm{L} \dagger$ & $0 / 7$ & 0 & $2 / 7$ & 29 & I & \\
\hline
\end{tabular}

\section{${ }^{*} \mathrm{p}<0.05$.}

†For items with incomplete data, the number of persons with available data is given as the denominator.

HDL-C, high-density lipoprotein cholesterol; LDL-C, low-density lipoprotein cholesterol; NNRTI, non-nucleoside reverse transcriptase inhibitor; SNP, single nucleotide polymorphism; TC, total cholesterol; TG, triglyceride.

supplementary table S3). The temporal difference in the maximum yearly $\mathrm{CD} 4$ between patients with normal TC and abnormal TC (at baseline and/or a rise above normal range following HAART) is shown in online supplementary figure. Multivariable analysis confirmed that both a low CD4 baseline count and increased TC following HAART were associated with poorer immune recovery.

The possible influence of dyslipidaemia and APO SNP on longitudinal CD4 trend over an extended period of up to 3 years was examined using GEE. Three APO gene mutations were included in the analyses: APOA5 $-1131 \mathrm{~T}>\mathrm{C}$ allele, APOA5 c.553G $>\mathrm{T}$ allele and APOC3 genotype 3238GG. The other input variables were: yearly time points, baseline CD4 (count $\leq 200 / \mu \mathrm{L}$ or $>200 / \mu \mathrm{L})$, abnormal TC $(\geq 5.17 \mathrm{mmol} / \mathrm{L}$ at baseline or 2-3 years after initiation of HAART, and/or the use of antilipid treatment), abnormal TG $(\geq 1.7 \mathrm{mmol} / \mathrm{L}$ at baseline or 2-3 years after initiation of HAART, and/or the use of antilipid treatment). Two sets of models were constructed for the exploration, one focusing on abnormal lipids and the other on the selected APO mutated alleles/genotype which have been shown to be associated either with hypertriglyceridaemia or with the ultimate $\mathrm{CD} 4$ recovery. The main results of GEE are displayed in table 3, using yearly maximum $\mathrm{CD} 4$ as the dependent variable. Abnormal TC but not TG was consistently associated with a poorer CD4 recovery, in conjunction with or without a low baseline CD4. On the other hand, the APOA5 mutated allele $-1131 \mathrm{~T}>\mathrm{C}$ was also a predictor of a weaker $\mathrm{CD} 4$ recovery over time. The impact was, however modest, as the association could not be demonstrated in the absence of a low baseline CD4 count $\leq 200 / \mu \mathrm{L}$. No statistically significant correlation can be found between the APOA5 mutated allele c.553G $>\mathrm{T}$ or the APOC3 mutated genotype 3238GG and the temporal trend of $\mathrm{CD} 4$ recovery.

\section{DISCUSSION}

In this study, we set out to examine the interrelationships between dyslipidaemia and immune recovery following the initiation of HAART in chronic HIV infection. Since hyperlipidaemia can be a result of a multitude of factors, we attempted to minimise, as far as possible, the effects of confounders by focusing on a 
Table 3 Results of linear GEE with annual maximum CD4 in the first 3 years of antiretroviral treatment as the outcome variable and the following parameter in the respective model: (1) mutated APOA5 allele -1131T>C; (2) mutated APOA5 allele c.553G>T; (3) mutated APOC3 3238GG genotype; (4) abnormal TC; (5) abnormal TG

\begin{tabular}{|c|c|c|c|c|c|c|c|c|c|c|c|c|c|c|c|}
\hline \multirow[b]{2}{*}{ Parameter } & \multicolumn{3}{|l|}{ (1) } & \multicolumn{3}{|l|}{ (2) } & \multicolumn{3}{|l|}{ (3) } & \multicolumn{3}{|l|}{ (4) } & \multicolumn{3}{|l|}{ (5) } \\
\hline & $\boldsymbol{\beta}$ & $95 \% \mathrm{Cl}$ & $\begin{array}{l}\mathbf{p} \\
\text { Value } \\
\end{array}$ & $\boldsymbol{\beta}$ & $95 \% \mathrm{Cl}$ & $\begin{array}{l}p \\
\text { Value } \\
\end{array}$ & $\boldsymbol{\beta}$ & $95 \% \mathrm{Cl}$ & $\begin{array}{l}\mathbf{p} \\
\text { Value } \\
\end{array}$ & $\boldsymbol{\beta}$ & $95 \% \mathrm{Cl}$ & $\begin{array}{l}\mathbf{p} \\
\text { Value } \\
\end{array}$ & $\boldsymbol{\beta}$ & $95 \% \mathrm{Cl}$ & $\begin{array}{l}\mathbf{p} \\
\text { Value }\end{array}$ \\
\hline $\begin{array}{l}\text { (Intercept) } \\
\text { Time point }\end{array}$ & 281 & 239 to 323 & $<0.001^{*}$ & 249 & 202 to 296 & $<0.001^{*}$ & 244 & 203 to 284 & $<0.001^{*}$ & 269 & 217 to 320 & $<0.001^{*}$ & 248 & 199 to 296 & $<0.001^{*}$ \\
\hline $\begin{array}{l}\text { Third } \\
\text { year }\end{array}$ & 399 & 350 to 448 & $<0.001^{*}$ & 404 & 352 to 455 & $<0.001^{*}$ & 402 & 351 to 453 & $<0.001^{*}$ & 392 & 330 to 454 & $<0.001^{*}$ & 396 & 331 to 460 & $<0.001^{*}$ \\
\hline $\begin{array}{l}\text { Second } \\
\text { year }\end{array}$ & 280 & 248 to 311 & $<0.001^{*}$ & 279 & 248 to 311 & $<0.001^{*}$ & 279 & 248 to 311 & $<0.001^{*}$ & 273 & 233 to 313 & $<0.001^{*}$ & 274 & 234 to 313 & $<0.001^{*}$ \\
\hline $\begin{array}{l}\text { First year } \\
\text { Baseline }\end{array}$ & $\begin{array}{l}175 \\
0\end{array}$ & $\begin{array}{l}157 \text { to } 193 \\
\text { ref }\end{array}$ & $<0.001^{*}$ & $\begin{array}{l}175 \\
0\end{array}$ & $\begin{array}{l}157 \text { to } 193 \\
\text { ref }\end{array}$ & $<0.001^{*}$ & $\begin{array}{l}175 \\
0\end{array}$ & $\begin{array}{l}157 \text { to } 193 \\
\text { ref }\end{array}$ & $<0.001^{*}$ & $\begin{array}{l}167 \\
0\end{array}$ & $\begin{array}{l}145 \text { to } 189 \\
\text { ref }\end{array}$ & $<0.001^{*}$ & $\begin{array}{l}167 \\
0\end{array}$ & $\begin{array}{l}145 \text { to } 189 \\
\text { ref }\end{array}$ & $<0.001^{*}$ \\
\hline Baseline CD & $4 \leq 200$ & & & & & & & & & & & & & & \\
\hline $\begin{array}{l}\text { Yes } \\
\text { No } \\
\text { APO gene } \\
\text { mutation }\end{array}$ & $\begin{array}{c}-189 \\
0 \\
A P O A\end{array}$ & $\begin{array}{l}-234 \text { to }-143 \\
\text { ref } \\
5-1131 \mathrm{~T}>\mathrm{C}\end{array}$ & $<0.001^{*}$ & $\begin{array}{c}-179 \\
0 \\
A P O A\end{array}$ & $\begin{array}{l}-233 \text { to }-125 \\
\text { ref } \\
5 \text { c. } 553 G>T\end{array}$ & $<0.001^{*}$ & $\begin{array}{c}-178 \\
0 \\
A P O C\end{array}$ & $\begin{array}{l}-256 \text { to }-130 \\
\text { ref } \\
33238 G G\end{array}$ & $<0.001^{*}$ & $\begin{array}{c}-151 \\
0\end{array}$ & $\begin{array}{l}-213 \text { to }-88 \\
\text { ref }\end{array}$ & $<0.001^{*}$ & $\begin{array}{c}-153 \\
0\end{array}$ & $\begin{array}{l}-219 \text { to }-87 \\
\text { ref }\end{array}$ & $<0.001^{*}$ \\
\hline $\begin{array}{l}\text { Yes } \\
\text { No }\end{array}$ & $\begin{array}{c}-44 \\
0\end{array}$ & $\begin{array}{l}-80 \text { to }-8 \\
\text { ref }\end{array}$ & $0.02^{*}$ & $\begin{array}{c}-17 \\
0\end{array}$ & $\begin{array}{l}-70 \text { to } 35 \\
\text { ref }\end{array}$ & 0.52 & $\begin{array}{l}17 \\
0\end{array}$ & $\begin{array}{l}-48 \text { to } 82 \\
\text { ref }\end{array}$ & 0.61 & & I & & & 1 & \\
\hline $\begin{array}{l}\text { Lipid } \\
\text { Yes } \\
\text { No }\end{array}$ & & l & & & I & & & & & $\begin{array}{l}\text { Abnorr } \\
-80 \\
0\end{array}$ & $\begin{array}{l}\text { mal TC } \\
-151 \text { to }-8 \\
\text { ref }\end{array}$ & $0.029^{*}$ & $\begin{array}{l}\text { Abnor } \\
-19 \\
0\end{array}$ & $\begin{array}{l}\text { mal TG } \\
-91 \text { to } 54 \\
\text { ref }\end{array}$ & 0.62 \\
\hline
\end{tabular}

${ }^{*} \mathrm{p}$ Value $<0.05$; abnormal TC=TC $>5.17 \mathrm{mmol} / \mathrm{L}$ either at baseline or $2-3$ years after initiation of HAART, and/or the use of antilipid treatment; abnormal TG=TG $\geq 1.7 \mathrm{mmol} / \mathrm{L}$ either at baseline or 2-3 years after initiation of HAART, and/or the use of antilipid treatment.

APO, apolipoprotein; GEE, generalised estimating equation; HAART, highly active antiretroviral therapy; TC, total cholesterol; TG, triglyceride. 
cohort composed of patients with the same ethnic background (ie, Chinese), and limiting the analyses to the situation in the first 2-3 years following the initiation of HAART. The temporal trend of dyslipidaemia was assessed, alongside the evaluation of the effects of selected APO SNPs. Our results confirmed that satisfactory $\mathrm{CD} 4$ achievement was negatively associated with a low baseline $\mathrm{CD} 4$ count, as has been reported by us and reviewed elsewhere. ${ }^{20} 21$ It is interesting to note, however, that dyslipidaemia did play an important role in the temporal pattern of immune recovery. Specifically, an elevation of plasma TC above $5.17 \mathrm{mmol} / \mathrm{L}$, rather than the absolute values at specific time point(s), in the 2-3 year period following initiation of HAART, was associated with poorer CD4 recovery. The latter's associations with TG, LDL-C and HDL-C could not be demonstrated. The effect of the boosted PI-based regimen on dyslipidaemia reported in other studies was also not seen in our cohort. ${ }^{22}$ Our results could be related to the clinical decision of attending physicians on restricting the use of PI to patients without baseline dyslipidaemia, such that the lipid profile of PI-treated patients was different from those on NNRTI. It is therefore difficult to compare between the two treatment groups in terms of temporal changes of plasma lipids. The relatively small proportion $(<5 \%)$ of patients requiring antilipid agents following HAART could be partly explained by the short observation period during which dyslipidaemia tended to be moderate.

From the perspective of host genetics, our results did not support a strong influence of the selected APO SNPs on immune recovery. At baseline, the associations between mutated APOA5 alleles -1131T $>\mathrm{C}$ and c. $553 \mathrm{G}>\mathrm{T}$ with high baseline TG were seen, confirming results of similar population studies on $\mathrm{HIV}^{12}$ and non-HIV patients. ${ }^{23}$ Our results on the associations between specific APO SNP and lipid profiles were not entirely the same as observations made in other reported studies. ${ }^{12} 13182224$ The discrepancies might have arisen from the differences in study design and/or the recruitment criteria applied in enrolling HIV patients. As regards immune recovery, the APOC3 3238GG genotype was shown to be associated with a better CD4 recovery 2-3 years after HAART, an observation not seen for other SNPs or genotypes for the eight selected APO genes under investigation; neither has this been reported in the literature. In assessing the temporal trend of CD4 increase using a GEE model, no correlation could be demonstrated with APOC3 3238GG. The same GEE model, however, showed that the APOA5 allele $-1131 \mathrm{~T}>\mathrm{C}$ was associated with a smaller CD4 increase over time, an observation similar to that reported by Echeverria et al. ${ }^{15}$ Other SNPs did not show any significant association with dyslipidaemia or CD4 achievement at any time points during the study, and which therefore have not been included in the GEE for further analysis. Though the selected APO SNP may predispose individuals to dyslipidaemia, there could also be strong influences of one's stage of HIV illness, nutritional status, diet, ethnicity, as well as the HAART regimens prescribed. The immunological impacts of SNP may therefore be hard to elicit if it is moderate, and especially so in the presence of the interplay between multiple factors in our cohort study. Since a CD4-guided approach was adopted as a standard practice for the initiation of HAART during the study period, the baseline pretreatment lipid profile is also likely to vary in accordance with the CD4 threshold adopted in different clinical cohorts.

The association between dyslipidaemia and immune recovery could be explained by the phenomenon of systemic inflammation, the latter long known to be a hallmark of both chronic HIV infection ${ }^{25}{ }^{26}$ as well as hyperlipidaemia. ${ }^{27}$ In chronically infected HIV patients, the inflammation burden was reported to be associated with elevated TC and TG, in the background of virological suppression following HAART. ${ }^{28}$ In the presence of ongoing activation of the innate and adaptive immune system, fuelled by the presence of proinflammatory cytokines, there is progressive destruction of CD4 cells. ${ }^{25}$ Early initiation of HAART with a PI-based regimen has been reported to promote rapid CD4 recovery. ${ }^{29}$ The impact of dyslipidaemia either at baseline or following treatment was, however, not examined in the latter study. Another small-scale study that involved the addition of an integrase inhibitor, a lipidneutral ARV, was shown to decrease the level of the inflammatory marker but failed to demonstrate any increase in CD4 counts. ${ }^{30}$ The use of an antilipid agent has in fact been examined as a means of reducing T-cell activation. There appeared to be a greater reduction of CD4 and CD8 cell activation, respectively, following statin, but improvement of the CD4 trend was not consistently demonstrated. ${ }^{31-33}$ In our cohort, abnormal levels of TC, TG, HDL-C and LDL-C were prevalent before HAART initiation. The results in our study confirmed the association between hyperlipidaemia, notably a rise from normal to high level following HAART, and a poorer CD4 recovery in the first 2-3 years after treatment initiation, with the APO gene polymorphism (notably APOA5 -1131T $>\mathrm{C}$ and APOC3 3238GG) playing a moderate role in parallel. The impacts of dyslipidaemia on immune activation might have counterbalanced the effects of HAART on CD4 recovery. Since the testing of inflammatory markers was not included in the original study design, the negative association between inflammation and CD4 recovery remains speculative. Other studies have suggested that CD4/CD8 inversion could be a marker of immune senescence and metabolic complication of chronic HIV infection, the latter characterised again by dyslipidaemia. ${ }^{34}$

We acknowledge that our study did carry some inherent limitations. By focusing on ARV-naïve patients with the same ethnic background, we were able to minimise the influences of confounders but had restricted 
ourselves to the analysis of a relatively small number of patients from the cohort. Generalisability of the results should therefore be made with caution. In the host genetic studies, we have only explored the impacts of eight selected APO SNPs while other genetic factors may knowingly also have contributed to dyslipidaemia. ${ }^{12} 1324$ In the assessment of immune recovery, CD4 counts were measured as the only marker of the body's response. The potential impacts of hyperlipidaemia on $\mathrm{T}$ cell activation and monocyte homoeostasis have not been evaluated. ${ }^{31-33} 35$ Neither have we examined the effects of treatment on the CD4/CD8 ratio, an indicator of effective immunological outcome that has recently been shown to be associated with the level of cumulative viraemia. ${ }^{36}$ The observation period was relatively short and may not allow conclusions to be drawn on the long-term impacts of dyslipidaemia, though the effects in the initial 2-3 years of HAART can be effectively elicited. Finally, the provision of antilipid in some patients may have partly complicated the clinical pictures. In our analyses, antilipid treatment at baseline and following ARV therapy were included as surrogates of dyslipidaemia, on the assumption that there could be relatively little or no impacts of such treatment on CD4 recovery in the first few years of HAART. Despite these drawbacks, this small study on a cohort of Chinese treatment-naïve patients, through genetic, statistical analyses and GEE, has enabled us to delineate the complex relationships between dyslipidaemia, APO gene polymorphisms and CD4 recovery. Further research on the biological pathways on inflammation and immune recovery would be crucial to better understand the situation so as to inform optimisation of ARV therapy.

Acknowledgements The authors gratefully acknowledge the support of Miss Mandy Li for her data entry and database management and also thank the Li Ka Shing Institute of Health Sciences for providing laboratory support.

Contributors S-SL conceptualised the study. CMN, M-PL and DP-CC developed the study protocols. DP-CC performed experiments on the APO gene SNP. M-PL coordinated the study at the clinic and collated the data in conjunction with DP-CC. RK-KL contributed to the initial data exploration, while N-SW worked on the final analyses described in this manuscript. CMN and DP-CC prepared the preliminary draft of the manuscript, which was subsequently revised by N-SW and S-SL. The final version of the manuscript was developed and edited by S-SL. All authors have read and approved the final version of the manuscript.

Funding This work was supported by funding from the Council for the AIDS Trust Fund (Project MSS173R), and the Health and Medical Research Fund (Project CU-15-A15), Hong Kong Special Administrative Region Government.

Disclaimer The funders were neither involved in the planning and design nor analyses arising from the study.

Competing interests None declared.

Patient consent Obtained.

Ethics approval Research Ethics Committee of The Joint Chinese University of Hong Kong-New Territories East Cluster, and Kowloon Central/Kowloon East Cluster of the Hospital Authority.

Provenance and peer review Not commissioned; externally peer reviewed.

Data sharing statement No additional data are available.
Open Access This is an Open Access article distributed in accordance with the Creative Commons Attribution Non Commercial (CC BY-NC 4.0) license, which permits others to distribute, remix, adapt, build upon this work noncommercially, and license their derivative works on different terms, provided the original work is properly cited and the use is non-commercial. See: http:// creativecommons.org/licenses/by-nc/4.0/

\section{REFERENCES}

1. El-Sadr WM, Mullin CM, Carr A, et al. Effects of HIV disease on lipid, glucose and insulin levels: results from a large antiretroviral-naive cohort. HIV Med 2005;6:114-21.

2. Grunfeld C, Kotler DP, Hamadeh R, et al. Hypertriglyceridemia in the acquired immunodeficiency syndrome. Am J Med 1989;86:27-31.

3. Oka F, Naito T, Oike M, et al. Correlation between HIV disease and lipid metabolism in antiretroviral-naïve HIV-infected patients in Japan. J Infect Chemother 2012;18:17-21.

4. Rose H, Woolley I, Hoy J, et al. HIV infection and high-density lipoprotein: the effect of the disease vs the effect of treatment. Metab Clin Exp 2006;55:90-5.

5. Samaras K. The burden of diabetes and hyperlipidemia in treated HIV infection and approaches for cardiometabolic care. Curr HIV/ AIDS Rep 2012;9:206-17.

6. Constans J, Pellegrin JL, Peuchant E, et al. Plasma lipids in HIV-infected patients: a prospective study in 95 patients. Eur J Clin Invest 1994;24:416-20.

7. Williams $\mathrm{P}, \mathrm{Wu} \mathrm{J}$, Cohn $\mathrm{S}$, et al. Improvement in lipid profiles over 6 years of follow-up in adults with AIDS and immune reconstitution. HIV Med 2009;10:290-301.

8. Asztalos BF, Matera R, Horvath KV, et al. Cardiovascular disease-risk markers in HIV patients. J AIDS Clin Res 2014;5:pii: 317.

9. Kanjanavanit S, Puthanakit T, Vibol U, et al. High prevalence of lipid abnormalities among antiretroviral-naive HIV-infected Asian children with mild-to-moderate immunosuppression. Antivir Ther (Lond) 2011;16:1351-5.

10. Floris-Moore M, Howard AA, Lo Y, et al. Increased serum lipids are associated with higher CD4 lymphocyte count in HIV-infected women. HIV Med 2006;7:421-30.

11. Azzoni L, Foulkes AS, Firnhaber C, et al. Metabolic and anthropometric parameters contribute to ART-mediated CD4+ T cell recovery in HIV-1-infected individuals: an observational study. J Int AIDS Soc 2011;14:37.

12. Arnedo $M$, Taffé $P$, Sahli $R$, et al. Contribution of 20 single nucleotide polymorphisms of 13 genes to dyslipidemia associated with antiretroviral therapy. Pharmacogenet Genomics 2007; 17:755-64.

13. Bonnet E, Genoux A, Bernard J, et al. Impact of genetic polymorphisms on the risk of lipid disorders in patients on anti-HIV therapy. Clin Chem Lab Med 2007;45:815-21.

14. Hsu LA, Ko YL, Chang CJ, et al. Genetic variations of apolipoprotein A5 gene is associated with the risk of coronary artery disease among Chinese in Taiwan. Atherosclerosis 2006;185:143-9.

15. Echeverria P, Guardiola M, González M, et al. Association between polymorphisms in genes involved in lipid metabolism and immunological status in chronically HIV-infected patients. Antiviral Res 2015;114:48-52.

16. Mattei J, Parnell LD, Lai CQ, et al. Disparities in allele frequencies and population differentiation for 101 disease-associated single nucleotide polymorphisms between Puerto Ricans and non-Hispanic whites. BMC Genet 2009;10:45.

17. Li S, Hu B, Wang $\mathrm{Y}$, et al. Influences of APOA5 variants on plasma triglyceride levels in Uyghur population. PLOS ONE 2014;9: e110258.

18. Tarr PE, Taffé $P$, Bleiber $G$, et al. Modeling the influence of APOC3, APOE, and TNF polymorphisms on the risk of antiretroviral therapy-associated lipid disorders. J Infect Dis 2005;191:1419-26.

19. Expert Panel on Detection, Evaluation, and Treatment of High Blood Cholesterol in Adults. Executive summary of the third report of the National Cholesterol Education Program (NCEP) expert panel on detection, evaluation, and treatment of high blood cholesterol in adults (adult treatment panel III). JAMA 2001;285:2486-97.

20. Naftalin CM, Wong NS, Chan DP, et al. Three different patterns of CD4 recovery in a cohort of Chinese HIV patients following antiretroviral therapy-a five-year observational study. Int J STD AIDS 2015;26:803-9.

21. Battegay $M$, Nüesch $R$, Hirschel $B$, et al. Immunological recovery and antiretroviral therapy in HIV-1 infection. Lancet Infect Dis 2006;6:280-7. 
22. Guardiola M, Ferré R, Salazar J, et al. Protease inhibitor-associated dyslipidemia in HIV-infected patients is strongly influenced by the APOA5-1131T->C gene variation. Clin Chem 2006;52:1914-19.

23. Liu Z-K, Hu M, Baum L, et al. Associations of polymorphisms in the apolipoprotein A1/C3/A4/A5 gene cluster with familial combined hyperlipidaemia in Hong Kong Chinese. Atherosclerosis 2010;208:427-32.

24. Zanone Poma B, Riva A, Nasi M, et al. Genetic polymorphisms differently influencing the emergence of atrophy and fat accumulation in HIV-related lipodystrophy. AIDS 2008;22:1769-78.

25. Ipp $\mathrm{H}$, Zemlin $\mathrm{A}$. The paradox of the immune response in HIV infection: when inflammation becomes harmful. Clin Chim Acta 2013;416:96-9.

26. Reus S, Portilla J, Sánchez-Payá J, et al. Low-level HIV viremia is associated with microbial translocation and inflammation. J Acquir Immune Defic Syndr 2013;62:129-34.

27. Siasos G, Tousoulis D, Oikonomou E, et al. Inflammatory markers in hyperlipidemia: from experimental models to clinical practice. Curr Pharm Des 2011;17:4132-46.

28. Viskovic K, Zidovec-Lepej S, Gorenec L, et al. Cardiovascular markers of inflammation and serum lipid levels in HIV-infected patients with undetectable viraemia. J Int AIDS Soc 2014;17:19548.

29. Rajasuriar R, Gouillou M, Spelman T, et al. Clinical predictors of immune reconstitution following combination antiretroviral therapy in patients from the Australian HIV Observational Database. PLoS ONE 2011;6:e20713.

30. Lichtenstein KA, Armon C, Nagabhushanam V, et al. A pilot study to assess inflammatory biomarker changes when raltegravir is added to a virologically suppressive HAART regimen in HIV-1-infected patients with limited immunological responses. Antivir Ther (Lond) 2012;17:1301-9.

31. Ganesan A, Crum-Cianflone N, Higgins J, et al. High dose atorvastatin decreases cellular markers of immune activation without affecting HIV-1 RNA levels: results of a double-blind randomized placebo controlled clinical trial. J Infect Dis 2011;203: 756-64.

32. Manfredi R, Calza L, Chiodo F. Long-term statin use does not act on the temporal trend of CD4 cell count in patients on virologically effective HAART. AIDS 2006;20:455-7.

33. Nakanjako D, Ssinabulya I, Nabatanzi R, et al. Atorvastatin reduces T-cell activation and exhaustion among HIV-infected cART-treated suboptimal immune responders in Uganda: a randomised crossover placebo-controlled trial. Trop Med Int Health 2015;20:380-90.

34. Saracino A, Bruno G, Scudeller L, et al. Chronic inflammation in a long-term cohort of HIV-infected patients according to the normalization of the CD4:CD8 ratio. AIDS Res Hum Retroviruses 2014;30:1178-84.

35. Han J, Zhao H, Ma Y, et al. Highly active antiretroviral therapy (HAART)-related hypertriglyceridemia is associated with failure of recovery of CD14lowCD16+ monocyte subsets in AIDS patients. Medicine (Baltimore) 2015;94:e1115.

36. Seng R, Goujard C, Krastinova E, et al. Influence of lifelong cumulative HIV viremia on long-term recovery of CD4+ cell count and CD4+/CD8+ ratio among patients on combination antiretroviral therapy. AIDS 2015;29:595-607. 